\title{
SERTÃO, SERTANEJAS E VIOLÊNCIA CONTRA A MULHER: ANÁLISE DOS DADOS ESTATÍSTICOS DO SERTÃO DE PERNAMBUCO
}

\section{Kalline Flávia Silva de Lira'}

Resumo: Este trabalho analisa os dados da violência doméstica e familiar contra a mulher na região do sertão do Araripe de Pernambuco. Os dados são disponibilizados pelas Secretarias de Defesa Social e da Mulher do estado, e são referentes aos anos de 2015 a 2018. Apesar dos números absolutos serem considerados pequenos, uma correlação entre os marcadores de gênero e regionalidade é uma forma mais fidedigna para analisar os registros. Percebeu-se que a região apresenta um número baixo de solicitações de medidas protetivas de urgência em relação aos números de ocorrências registradas em relação à violência doméstica e familiar contra a mulher.

Palavras-chave: Violência contra a mulher; gênero; regionalidade.

\begin{abstract}
This article analyzes the data on domestic and family violence against women in the Sertão do Araripe region of Pernambuco. The data are made available by the Social Defense and Women's State Secretariats, from 2015 to 2018. Although absolute numbers are considered small, a correlation between gender and regionality markers is a more reliable way to analyze records. We noted that the region presents a low number of requests for urgent protective measures in relation to the numbers of occurrences registered regarding domestic and family violence against women.
\end{abstract}

Keywords: Violence against women; gender; regionality.

\section{Introdução}

Segundo Minayo (2007, p. 23), não há conhecimento de nenhuma sociedade em que não existiu violência, sendo que algumas são mais violentas do que outras, e o fenômeno "consiste no uso da força, do poder e de privilégios para dominar, submeter e provocar danos a outros: indivíduos, grupos e coletividades". Para a autora, existem determinadas violências

1 Psicóloga. Doutoranda em Psicologia Social na Universidade do Estado do Rio de Janeiro, Brasil. E-mail: kalline_lira@hotmail.com. Orcid: 0000-0002-2927-4748 
que perduram mais do que outras e que existem em praticamente todas as sociedades: é o caso da violência de gênero, principalmente aquela perpetrada pelo homem contra a mulher.

A violência de gênero se apresenta como uma forma de dominação que existe numa sociedade, sem fazer distinção de classe social, cor, etnia, faixa etária, religiosidade e orientação sexual ou política. Segundo Minayo (2007), sua expressão maior é o machismo naturalizado nas socializações realizadas entre homens e mulheres. Assim, a violência contra as mulheres que acontecem sobretudo no âmbito familiar e conjugal é uma das maiores expressões da violência de gênero.

Conforme Santos e Izumino (2005), a expressão "violência contra a mulher" começou com a segunda onda do movimento feminista na década de 1960, que tinha como principais bandeiras a autonomia do corpo e o direito à sexualidade e ao prazer. No Brasil, as produções acadêmicas começaram apenas na década de 1980, colocando a violência contra a mulher como tema importante nos estudos feministas.

Minayo (2007) alerta que, muitas vezes, algumas violências são "naturalizadas" e, por isso, as pessoas que as cometem acreditam que estão fazendo algo normal. No entanto, como a violência é uma construção histórica e que muda de acordo com cada sociedade que a produz, ela pode aumentar ou diminuir, em conformidade com sua construção social. Neste sentido, é necessário refletir as questões históricas sobre os direitos das mulheres, que durante muito tempo tiverem seu papel na sociedade limitado aos cuidados com o lar e com a família, tendo direitos básicos, como direitos políticos, educação e a liberdade de ir e vir cerceados.

De acordo com Blay (2003), desde a metade do século XIX até depois da Primeira Guerra Mundial, as mulheres foram conquistando direitos importantes, em consequência da mudança econômica e cultural ocorrida no Brasil. $\bigcirc$ aumento da industrialização e da urbanização trouxe a possibilidade das mulheres ocuparem o espaço público, por meio do acesso à educação e ao trabalho, exercendo, portanto, maior autonomia e assumindo papéis mais ativos no meio social. No entanto ainda continuavam subordinadas à avaliação masculina.

Blay (2003) lembra que o Código Civil Brasileiro de 1916 considerava as mulheres como relativamente capazes, e não era permitido trabaIhar sem a autorização de seus maridos, já que se afirmava que o trabalho fora de casa acarretaria uma desagregação da família. Importante também 
mencionar que o Código Civil de 1916 ainda não trazia a possibilidade de divórcio (BRASIL, 1916). A extinção da necessidade de autorização dos maridos para que as mulheres pudessem trabalhar fora de casa aconteceu em 1962, com o Estatuto da Mulher Casada. Já a Lei do Divórcio foi promulgada somente em 1977.

Apesar desses avanços legislativos e da evolução sociocultural, além do Brasil ser signatário de importantes convenções internacionais, somente após o Estado brasileiro ser condenado pela Organização dos Estados Americanos (OEA) é que surgiu a Lei no 11.340/2006 - a Lei Maria da Penha -, considerada um marco na legislação sobre o enfrentamento à violência doméstica e familiar contra a mulher. Porém, mesmo com a implantação da Lei, continuam a existir muitos casos de violência doméstica e familiar contra a mulher no país.

Segundo o último Mapa da violência produzido sobre os homicídios de mulheres no Brasil, baseando-se nos dados disponibilizados em 2014 pelo Sistema de Informação de Agravos de Notificação (Sinan) do Sistema Único de Saúde (SUS), de cada três pessoas atendidas por motivo de violência, duas eram mulheres, ou seja, precisaram de algum atendimento de saúde em consequência das violências. A pesquisa aponta que a cada dia, no ano de 2014, 405 mulheres precisaram de atendimento em alguma unidade de saúde, devido à violência sofrida, seja doméstica, sexual, entre outras (WAISELFISZ, 2015).

Ainda segundo dados apresentados pelo Mapa, em 2003, Pernambuco ocupava $\circ 5^{\circ}$ lugar entre os estados com maior taxa de homicídios de mulheres: 6,5 para cada 100 mil habitantes, bem acima da média nacional, de 4,4 para o mesmo número de habitantes. Em 2013, o ranking melhorou consideravelmente, caindo para o $15^{\circ}$ lugar, com taxa de 5,5/100 mil habitantes, mas ainda acima da média nacional, de 4,8/100 mil. Com essa taxa, o Brasil ocupa o $5^{\circ}$ lugar entre os países que mais comentem violência contra a mulher (WAISELFISZ, 2015). Dois outros dados importantes são apresentados no documento citado: no que se refere à violência não letal, o domicilio é o local em $71,9 \%$ dos casos de violência contra a mulher; e, em $67,2 \%$ dos casos, o agressor era um parente imediato, parceiro ou ex-parceiro da vítima (WAISELFISZ, 2015), reforçando a desigualdade da mulher nas relações domésticas e familiares.

Este trabalho visa a analisar os dados sobre violência doméstica e familiar contra a mulher na Região de Desenvolvimento (RD) sertão do Araripe, 
no estado de Pernambuco. Para esta análise, são apresentados os dados dos registros da violência doméstica e familiar, bem como o cruzamento desses dados com as solicitações das medidas protetivas, como abrigamentos e monitoramento eletrônico. Verificaram-se também as taxas de homicídios de mulheres e feminicídio na região escolhida para o estudo.

No que se refere à metodologia, a pesquisa se desenvolveu pelo método quantitativo, por meio da coleta de dados estatísticos disponibilizados pelas Secretarias da Mulher e de Defesa Social do estado de Pernambuco. Os dados são referentes aos anos de 2015 a 2018, divulgados em 2019, concernentes à região pesquisada.

\section{Violência contra as mulheres e as legislações brasileiras}

A atuação dos movimentos de mulheres teve papel fundamental para garantir a igualdade entre os sexos, exposto na Constituição Federal de 1988. A Carta Magna passou a declarar que "homens e mulheres são iguais em direitos e obrigações" (BRASIL, 1988, art. $5^{\circ}$ ). Além disso, o artigo 226, no parágrafo $5^{\circ}$, aponta que "os direitos e deveres referentes à sociedade conjugal são exercidos igualmente pelo homem e pela mulher" e, em seguida, no parágrafo $8^{\circ}$, diz que "O Estado assegurará a assistência à família na pessoa de cada um dos que a integram, criando mecanismos para coibir a violência no âmbito de suas relações" (BRASIL, 1988, art. 226).

Essa garantia formal, no entanto, coexistiu com outras legislações discriminatórias, como o já citado Código Civil de 1916, que vigorou até 2002. $\bigcirc$ antigo Código outorgava ao homem o comando da família, apontando que "O marido é o chefe da sociedade conjugal, função que exerce com a colaboração da mulher" (BRASIL, 1916, art. 233). Além disso, o Código permitia que o homem administrasse os bens comuns e os particulares da mulher. Assim, ao colocar a mulher como "relativamente capaz", o controle dos homens resultava na violência contra as mulheres.

Em 1995 foi sancionada a Lei $n^{0}$ 9.099, que implantou os Juizados Especiais Criminais (JECrim), estabelecendo competências e normas específicas para seu funcionamento. Assim, esses Juizados teriam como competência os crimes considerados de menor potencial ofensivo, em que a pena máxima não seria superior a um ano, aplicada geralmente aos crimes de ameaça e lesão corporal leves, de acordo com os artigos 129 e 147 do 
Código Penal. Tais tipos de crimes eram os mais comuns relacionados à violência doméstica e familiar.

Assim, a maioria das violências contra as mulheres, dentro do âmbito doméstico e familiar, era considerada como de menor potencial ofensivo. Com essa interpretação, a violência contra a mulher passou a ser abordada de maneira secundária, diminuindo a gravidade do problema, além de criar mecanismos alternativos de cumprimento de pena para o agressor. Para Piovesan e Pimentel (2011, p. 113), naquele momento, os crimes de violência contra a mulher "ora eram vistos como mera 'querela doméstica', ora como reflexo de um ato de 'vingança ou implicância da vítima', ora decorrentes da culpabilidade da própria vítima, no perverso jogo de que a mulher teria merecido, por seu comportamento, a resposta violenta".

Diante disso, mesmo que a Constituição Federal e os tratados internacionais, como a Convenção de Eliminação de Todas as Formas de Discriminação contra a Mulher e a Convenção de Belém do Pará, sejam considerados grandes avanços no entendimento dos direitos das mulheres como direitos humanos, e no modo de interpretar o fenômeno da violência contra a mulher, a Lei n 9.099/1995 trouxe regressão ao tratar a ameaça e a lesão corporal leve como crimes de menor potencial ofensivo, além de prever a aplicação de penas alternativas (BRASIL, 1995).

Foi nesse contexto da permanência de impunidade dos agressores que surgiu a Lei $n^{0} 11.340 / 2006$, conhecida como Lei Maria da Penha (BRASIL, 2006), visando a proteger as mulheres em situação de violência doméstica e familiar, bem como punir seus agressores. $\bigcirc$ Brasil foi condenado pela Comissão Interamericana de Direitos Humanos por negligência e omissão no que se refere aos casos de violência doméstica. Conforme Piovesan e Pimentel (2011, p. 110), o caso de Maria da Penha "permitiu, de forma emblemática, romper com a invisibilidade que acoberta este grave padrão de violência de que são vítimas tantas mulheres, sendo símbolo de uma necessária conspiração contra a impunidade".

A Lei Maria da Penha define violência doméstica e familiar contra a mulher, afinada com o conceito utilizado na Convenção de Belém de Pará, como qualquer ação ou omissão que seja baseada no gênero, e que possa causar morte, lesão, sofrimento físico, sexual ou psicológico e dano moral ou patrimonial (BRASIL, 2006). A Lei também institui cinco tipos de violências doméstica e familiar: física, psicológica, sexual, patrimonial e moral. 
reconhecimento das diversas formas de violência é essencial para prevenção, identificação e penalização das violências contra as mulheres.

A Lei também trouxe a possibilidade de aplicar medidas mais rigorosas em relação aos agressores, que antes respondiam pela Lei n 9.099/1995, por compreender a violência doméstica como crime de menor potencial ofensivo, em que as punições eram restritas às penas alternativas, como pagamento de cestas básicas ou prestação de serviços comunitários. A Lei Maria da Penha passa a atuar em três eixos principais: o criminal; a proteção e assistência; e prevenção e educação. Destacam-se a mudança em relação à punição, pois ficou garantida a prisão em flagrante, a retomada do inquérito policial e o veto da aplicação da Lei n ${ }^{0}$ 9.099/1995.

De acordo com os dados do Mapa da Violência, o domicílio da mulher é o local do homicídio em 27,1\% dos casos (WAISELFISZ, 2015). Embora não represente a maioria dos casos, o dado é significativo se for realizada uma análise de gênero, ou seja, o domicilio não é tão relevante nos homicídios masculinos. Já o Atlas da violência 2019 aponta que 4.936 mulheres foram assassinadas em 2017, correspondendo a treze vítimas por dia. De 2012 a 2017, os homicídios fora da residência caíram 3,3\%, enquanto os ocorridos dentro de casa cresceram 17,1\%. Simultaneamente, o número de mulheres mortas por arma de fogo dentro da residência cresceu $28,7 \%$ (CERQUEIRA et al., 2019). Esses dados lançam uma questão primordial: está se falando de homicídio de mulheres ou de feminicídio?

\section{Feminicídio}

A partir da Lei Maria da Penha, o fenômeno da violência doméstica e familiar contra as mulheres ficou cada vez mais evidente para a sociedade brasileira. Porém, apesar dos avanços trazidos pela Lei, algumas mudanças ainda eram necessárias. Como exemplo, cita-se a perpetuação do homicidio de mulheres. A partir dos anos 2000, vários países da América Latina incluíram o feminicídio em suas legislações, devido às pressões da sociedade civil, dos movimentos feministas e da influência das organizações internacionais.

Conforme Blay (2003), durante a década de 1970, teve início o movimento pela defesa da vida das mulheres e pela punição dos assassinos. As principais estratégias utilizadas na época para defender os homens, mesmo quando o réu confessava, eram: demonstrar o bom caráter do assassino, difamar a vítima e mostrar como ela levou o homem a cometer o crime. 
Eleonora Menicucci define feminicídio como "um crime de ódio e seu conceito surgiu na década de 1970 para reconhecer e dar visibilidade à morte violenta de mulheres resultante da discriminação, opressão, desigualdade e violências sistemáticas" (PRADO; SANEMATSU, 2017, p. 11). Dentro desse contexto, o feminicídio não é um evento isolado, sendo resultado de uma série de violências e abusos.

$\bigcirc$ crime de feminicídio foi definido legalmente no Brasil a partir da Lei ${ }^{0} 13.104 / 2015$, que alterou o artigo 121 do Código Penal, incluindo - tipo penal como circunstância qualificadora do crime de homicídio (BRASIL, 2015). A Lei surgiu pela recomendação da Comissão Parlamentar Mista de Inquérito (CPMI) sobre Violência contra a Mulher, com vistas a diminuir a impunidade desses crimes e dar maior visibilidade às vítimas. Antes da instauração da Lei, o ato de matar uma mulher simplesmente pela qualidade de sexo feminino era considerado um homicídio qualificado por motivo fútil ou torpe, não havendo qualquer sanção especial para punir tal prática.

Com a alteração do Código Penal pela Lei n ${ }^{0} 13.104 / 2015$, o feminicídio começou a ser considerado como "o assassinato de uma mulher cometido por razões da condição de sexo feminino". Acrescentaram-se ao $\S 2^{\circ}$-A do artigo 121 os critérios que definem as razões de condição de sexo feminino: quando o crime envolver violência doméstica e familiar; e menosprezo ou discriminação à condição de mulher.

A pena para esses tipos de crime varia de doze a trinta anos de reclusão. $\bigcirc$ aumento da pena em um terço até a metade pode ocorrer nas seguintes condições: crime cometido quando a mulher estiver grávida ou nos três meses posteriores ao parto; contra pessoa menor de catorze anos ou maior de sessenta anos, ou com alguma deficiência; e na presença de descendente ou ascendente da vítima. Vale salientar que a Lei $n^{0} 13.104 / 2015$ incluiu a forma qualificada de homicídio no rol dos crimes hediondos, assim como o estupro e o genocídio, alterando também a Lei n ${ }^{0} 8.702 / 1990$.

Reafirmando que as mulheres são mais vulneráveis no ambiente doméstico e nas suas relações afetivas e familiares, um tópico que merece destaque dentro da Lei Maria da Penha é a medida protetiva de urgência, considerada um mecanismo que tem o intuito de proteger a integridade física das mulheres e de outros membros da familia em situação de violência. 


\section{Medidas protetivas de urgência}

A Lei Maria da Penha, conforme pontuado anteriormente, atua em três áreas distintas, sendo uma delas a de proteção e assistência. As medidas de proteção são destinadas, principalmente, a assegurar a integridade física e os direitos das mulheres em situação de violência doméstica e familiar. No entanto, segundo Pasinato (2010), muitas vezes há uma enorme lacuna nos relatos dos fatos realizados pela autoridade policial, tendo como consequência a escassez de elementos suficientes para que o Poder Judiciário tenha condições de determinar uma medida protetiva que seja verdadeiramente eficaz na situação apresentada.

A Lei n ${ }^{0} 11.340 / 2006$ prevê dois tipos de medidas protetivas de urgência: as que obrigam o agressor e as que se dirigem às mulheres. As medidas inseridas no primeiro grupo estão previstas no artigo 22 e visam a obrigar o agressor a não cometer determinadas ações. Dentre as principais medidas citam-se: o afastamento do lar, domicílio ou local de convivência com a ofendida; a proibição de aproximação da vítima, seus familiares e testemunhas, sendo fixado um limite mínimo de distância entre o agressor e estes; a vedação de contato com a ofendida, seus familiares e testemunhas, por qualquer meio de comunicação, como também a proibição de frequentar determinados lugares, a fim de manter a integridade física e psíquica da vítima. Além disso, o agressor fica com o porte de arma de fogo suspenso, assim como suspendem-se as visitas aos menores dependentes, podendo o agressor ser obrigado a prestar alimentação a eles.

Já as medidas do segundo grupo estão dispostas nos artigos 23 e 24 da Lei, sendo medidas voltadas a proteger mulheres em situação de violência. Citam-se as principais: o afastamento da vítima do lar, o encaminhamento desta e de seus filhos ao programa oficial ou comunitário de proteção, assim como sua recondução ao domicílio após o afastamento do agressor (BRASIL, 2006).

A Lei também traz medidas que têm o intuito de proteger o patrimônio conjugal. Assim, é vedada a compra, a venda e a locação de propriedade comum, podendo os bens que foram subtraídos pelo agressor ser restituidos, suspendem-se as procurações conferidas pela ofendida ao agressor, como também pode-se exigir a prestação de caução provisória para sanar as perdas e os danos oriundos da violência (BRASIL, 2006).

No que se refere às medidas protetivas, a Lei Maria da Penha foi alterada pela Lei n ${ }^{13.827 / 2019}$. Essa alteração no artigo $12-\mathrm{C}$ trouxe mudanças 
no que diz respeito à concessão das medidas protetivas de urgência, com o objetivo de garantir o afastamento do agressor de maneira mais rápida possivel. Dessa forma, os(as) delegados(as) de polícia poderão conceder medidas protetivas de urgência quando não houver comarca judicial na cidade, assim como policiais também poderão conceder tais medidas quando não houver comarca judicial na cidade e na ausência de delegado(a) (BRASIL, 2019).

Antes da alteração mencionada, as medidas protetivas eram apenas requeridas em delegacias de polícia. $\bigcirc$ trâmite ocorria de forma que era necessário lavrar um boletim de ocorrência e solicitar a medida à autoridade policial. Em seguida, o(a) delegado(a) deveria protocolar tal pedido à autoridade judicial, que teria o prazo legal de 48 horas para examinar o pedido. Em casos de maior urgência, a vítima tinha a possibilidade de se reportar diretamente ao(à) juiz(a) ou ao Ministério Público por meio de uma petição. Ressalta-se ainda que, caso as medidas sejam lavradas pelo(a) delegado(a) ou policial, deverão ser comunicadas ao Ministério Público no prazo de 24 horas, tendo o juiz igual prazo para manter, reformar ou retirar (BRASIL, 2019).

Salienta-se que, para solicitar as medidas protetivas, as mulheres não necessitam estar acompanhadas de advogados(as) e independem de inquérito policial ou processo penal. A escuta da outra parte também é dispensada, podendo o(a) juiz(a) deferir a medida de maneira liminar, e somente após a expedição da medida é que o agressor é comunicado, passando a estar obrigado a partir do recebimento da notificação. Por ser recente, ainda não há possibilidades de averiguar se essa mudança permitiu algum avanço na efetivação da proteção da mulher em situação de violência.

\section{Regionalidade, gênero e violência}

Conforme Molion e Bernardo (2002), o sertão nordestino é a região mais seca do Brasil e está inserido numa área tropical que apresenta baixos totais pluviométricos, com precipitação não ultrapassando $400 \mathrm{~mm}$ anuais em diversos locais, tornando-se anômalo em relação a outras regiões na mesma faixa latitudinal. Em função do clima, sua vegetação é composta por árvores e arbustos, que recebe a denominação de caatinga, sendo, portanto, suscetível à desertificação.

Para Albuquerque Júnior (1994), a descoberta do tema da seca como discurso que emocionava e mobilizava recursos e obras inaugurou um novo motivo diante da decadência das atividades econômicas da região. A seca não passa 
a ser o tema central apenas no discurso dos representantes políticos, mas amplia-se também a outros setores. A reelaboração da região se dá no plano cultural, mais do que no político. Assim, atreladas ao fenômeno da seca, vêm as temáticas do cangaço e do messianismo, que apenas reafirmam a imagem do nordestino como homem violento e fanático, compreendendo o Nordeste como uma terra sem lei, muitas vezes subjugada ao terror dos bandidos.

Para Albuquerque Júnior (1994), ao falar do(a) nordestino(a), deve-se evitar cair na estereotipia, pois é perigoso considerar-se no direito de dizer quem é o outro, reduzindo-o a poucas palavras. $\bigcirc$ autor ressalta que 0 Nordeste e os(as) nordestinos(as) são invenções que se sustentam pelas próprias relações de poder vigentes nessa região. Nesse sentido, os sujeitos são mencionados com frequência como derrotados, oprimidos, discriminados e explorados, principalmente pelas regiões Sul e Sudeste do país. Em contrapartida, os(as) próprios(as) nordestinos(as) reiteram e propagam o discurso do atrasado, do pobre, do necessitado. Para o autor, definir uma região não é pensá-la a partir de uma unidade, e sim como um grupo de enunciados e imagens que se repetem, em determinada proporção, em diversos discursos e épocas, a partir de diferentes estilos.

Assim, o Nordeste foi uma espécie de invenção regional, a partir de uma tentativa de romper com a antiga dualidade Norte versus Sul, em um momento em que o Norte começava a perder o poder devido às mudanças ocorridas com o fim da escravidão, além da crise da produção açucareira. Em contrapartida, o Sul se fortalecia com o desenvolvimento urbano e industrial. Uma redistribuição dos territórios no país aconteceu, de forma que o Nordeste tentou evitar a chegada da modernidade, voltando-se para uma tradição e memória reinventadas por meio de uma prática discursiva autocentrada. Assim, os principais temas escolhidos para falar da região são aqueles que sensibilizam a opinião pública nacional e que podem trazer novos recursos ao local: a seca, o cangaço, o messianismo e as lutas pelo controle do Estado (ALBUQUERQUE JÚNIOR, 1994).

Para compreender a violência contra as mulheres no sertão nordestino, é necessário fazer a intersecção entre os conceitos de gênero e regionalidade, porque, neste contexto, discutir gênero passa a ser discutir região também. Para Albuquerque Júnior (2013, p. 90), "o Nordeste precisava de um novo homem capaz de resgatar essa virilidade, um homem capaz de reagir a esta feminização que o mundo moderno, a cidade, a industrialização e a república haviam trazido". A construção da figura do nordestino está extremamente 
imbuída do sentimento de preservação da região, intensificada na militância regionalista e tradicionalista. Assim, suas características são definidas como um tipo tradicional, em defesa de um passado que também é considerado tradicional, patriarcal, em oposição ao moderno, na sociedade efeminada. $\mathrm{Ou}$ seja, o nordestino é compreendido como uma pessoa no sentido contrário ao mundo moderno, pois renunciaria as superficialidades, sendo um homem de costumes conservadores, rústico, áspero, masculino.

Os tipos regionais existentes, como o sertanejo, o praieiro, o brejeiro, passam a ser agrupados numa única categoria: a de nordestinos. Todos possuíam elementos em sua composição que naturalmente se aproximavam dessa nova figura regional. Vale destacar que o que existe de comum entre esses tipos, no tocante às questões de gênero, suas relações e violências, são os códigos de virilidade e masculinidade que agenciam, dando visibilidade ao discurso regional. Assim, conforme pontua Albuquerque Júnior (2013), o nordestino passa a ser definido como macho por excelência, pela sua capacidade viril de reerguer uma região que foi invadida e deturpada por interesses e valores estranhos.

resultado dos processos de construção dos códigos e das práticas sociais traz a construção de um nordestino atrelado ao seu território. Essa construção também é consequência da subjetividade propagada nos corpos e nos comportamentos manifestados pelos sujeitos dentro dos espaços sociais. Para Oliveira (2002), é possivel compreender a lógica de dominação masculina produzida a partir de uma produção cultural e, historicamente, têm intensificado as divisões de gênero, além de aumentar o significado das práticas sociais definidas para cada gênero.

Os aspectos de violência como elemento formador da identidade masculina estão intrinsecamente ligados ao processo de construção/invenção do Nordeste. Como afirma Albuquerque Júnior (1998, p. 3), "a violência é neste discurso um componente da sociabilidade no Nordeste, uma característica da própria forma de ser do nordestino e, mais acentuadamente, um dos elementos que comporiam os atributos da masculinidade nesta região". Em resumo, nesta região, não haveria lugar para homens fracos e covardes.

Outra característica presente é o desejo atribuído ao masculino, em que os homens estão sempre desejando ardentemente as mulheres, um desejo físico, de carne, violento. Para Albuquerque Júnior (1998), a imagem do desejo geralmente é associada à imagem da terra, do fogo, aos elementos primitivos. $O$ desejo masculino de penetrar e de dominar parece 
ser compreendido como o princípio ordenador do próprio social. Por outro lado, o desejo feminino deve ser reiteradamente negado e silenciado, ou transformado em desejos amorosos e maternos. Dessa forma, o desejo feminino deve ser constantemente contido, ou poderá trazer o caos, subvertendo a ordem social dominada pelos homens.

No que se refere à construção dos papéis masculino e feminino, é importante compreendê-los enquanto processo culturalmente constituído. Assim, as produções do ser feminino e do ser masculino no Nordeste respondem também a um projeto de sociedade. Como afirma Louro (1996, p. 26), "há um investimento continuado e produtivo dos próprios sujeitos na determinação de suas formas de ser ou 'jeitos de viver', sua sexualidade e seu gênero".

$O$ conceito de gênero adotado surge das reflexões feministas que compreendem gênero como categoria analítica, histórica e social, contestando o determinismo biológico na produção das iniquidades. Para Scott (1995), as discussões de gênero devem analisar os pactos socais realizados para as instituições dos papéis de homens e mulheres. $\bigcirc$ conceito de gênero significa, portanto, uma categoria que se dirige a apreender as relações de poder existente entre os sexos. Assim, homens e mulheres, masculino e feminino, continuam sendo produzidos no imaginário discursivo e nas relações de saber/ poder que se cruzam nas práticas sociais. De forma geral, a imagem da mulher é ligada à esfera doméstica e da educação dos filhos, atrelada à ideia de cuidado e da obrigação de agradar o homem e servi-lo doméstica e sexualmente. Já o homem continua atrelado ao espaço público, do trabalho, mas também do lazer e da farra, espaços historicamente destinados ao masculino.

Segundo Albuquerque Júnior (1998), esse imaginário discursivo que vincula masculinidade e violência ao ser nordestino não se tece apenas de imagens do passado. Isso porque o conjunto de imagens e enunciados ainda existe no presente, fazendo parte dele e, com isso, produz determinadas subjetividades que servem de modelos para práticas, além de produzir um saber sobre o ser homem e o ser mulher, que influenciam as relações entre os gêneros. Essas relações podem, portanto, reproduzir e perpetuar as violências existentes na época do cangaço e do coronelismo, fenômenos sociais importantes e característicos principalmente do sertão nordestino.

No entanto, pode-se perceber que esse componente de violência, mesmo de maneira simbólica, existente nas relações entre os gêneros, vem se modificando historicamente, à medida que as relações sociais e de poder se alteram. É possivel verificar a existência de novos padrões de 
sociabilidade e sensibilidade. Para Albuquerque Júnior (1998), isso tornaria a figura do macho nordestino obsoleta, ocasionando uma crise de identidade justamente por não ser um processo natural, mas historicamente construído. Então, da mesma maneira que foi construída, essa identidade pode ser desconstruída. No entanto essa desconstrução nem sempre é fácil, pois ressignificar lugares de poder pode ocasionar a renúncia das vantagens conquistadas pela imposição do gênero.

\section{A violência contra a mulher no sertão do Araripe}

principal objetivo desse estudo foi analisar os dados sobre violência doméstica e familiar contra a mulher na RD sertão do Araripe, no estado de Pernambuco. Os dados aqui utilizados são referentes aos anos de 2015 a 2018. Este recorte temporal se deve ao fato de terem sido os anos em que os cruzamentos dos dados foram mais completos. Os dados dizem respeito aos registros da violência doméstica e familiar, das solicitações das medidas protetivas, como abrigamentos e monitoramento eletrônico, além das taxas de homicídios de mulheres e feminicídios. Os números analisados são disponibilizados pelas Secretarias da Mulher e de Defesa Social do estado de Pernambuco.

A RD sertão do Araripe é composta por dez municípios: Araripina, Bodocó, Exu, Granito, Ipubi, Moreilândia, Ouricuri, Santa Cruz, Santa Filomena e Trindade. A região é conhecida como polo gesseiro pernambucano, pois todas as cidades estão envolvidas na extração da gipsita (matéria- prima utilizada para a produção do gesso). A atividade é muito importante, sendo a região responsável por aproximadamente $95 \%$ de todo o gesso produzido no país.

Apesar disso, conforme os dados do último censo realizado em 2010, apenas aproximadamente $12 \%$ da população economicamente ativa na região desenvolviam atividades ligadas às indústrias de extração e transformação de gesso. Em torno de $45 \%$ desenvolviam atividades agropecuárias, mesmo que informalmente. A maior parte realiza cultivo de mandioca e de diferentes tipos de frutas e, com frequência, a mão de obra é informal, sendo essencialmente um trabalho familiar de autoconsumo e venda dos excedentes (INSTITUTO BRASILEIRO DE GEOGRAFIA E ESTATÍSTICA, 2011).

Pesquisa realizada pela Fundação Joaquim Nabuco em três municipios da região aponta que a faixa etária da maioria dos chefes de familia era de 
31 a 40 anos, e que cerca de $70 \%$ deles era do sexo masculino. Destes, $80 \%$ recebiam, em média, um salário mínimo por mês. Na região há um grande efetivo de famílias que participam dos programas federais de distribuição de renda, como o Programa Bolsa Família (PBF) (FUNDAÇÃO JOAQUIM NABUCO, 2006).

Em relação aos maiores municípios da região, considerados polos e com maior produto interno bruto (PIB), temos: em Ouricuri, 60,91\% da população como beneficiária do PBF, totalizando 12.005 familias, além de 36.883 famílias em situação de extrema pobreza; Araripina apresenta 64,06\% da população como beneficiária do PBF, equivalente a 16.974 familias, além de 48.501 familias em situação de extrema pobreza (PERNAMBUCO, 2019a).

Segundo Prado (2003), essa região se caracteriza por apresentar hegemonicamente solos rasos e jovens, e clima semiárido, com chuvas escassas e concentradas entre três a quatro meses do ano. Seu clima é tropical e semiárido quente, com temperatura média anual de $24^{\circ} \mathrm{C}$. Em consequência, o clima é um complicador para a produção agrícola e para as condições de vida na região.

$\bigcirc$ primeiro dado analisado se refere aos registros de violência doméstica e familiar contra as mulheres. $\bigcirc$ sertão do Araripe apresentou média anual de 802 registros, entre os anos de 2015 e 2018, conforme o Gráfico 1.

Gráfico 1: Registro de violência doméstica e familiar contra as mulheres (2015 - 2018)

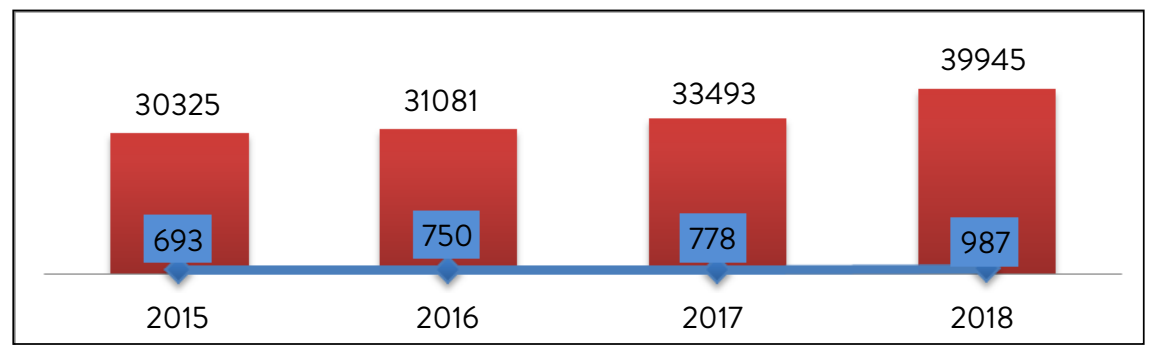

Legenda: $\quad$ Registro de casos de violência doméstica e familiar contra mulheres em Pernambuco; $\rightarrow$ Registro de casos de violência doméstica e familiar contra as mulheres no sertão do Araripe.

Fonte: Pernambuco (2019b).

Analisando o Gráfico 1, percebe-se que a RD sertão do Araripe concentra $2,3 \%$ dos registros de casos de violência doméstica e familiar contra mulheres de Pernambuco no ano de 2017, e 2,4\% no ano de 2018. Dados da Secretaria de Defesa Social (PERNAMBUCO, 2019c) apontam que o município de Araripina teve 290 registros no ano de 
2017, e 319 no ano de 2018. O município de Ouricuri teve 155 registros em 2017, e 190 em 2018.

A partir dos dados apresentados, calculou-se a taxa por 100 mil habitantes, com base na estimativa populacional do Instituto Brasileiro de Geografia e Estatística (IBGE)2. Em 2017, Recife, a capital e cidade mais populosa do estado, apresentou taxa de 619,6 crimes contra a mulher a cada 100 mil habitantes. Araripina tem taxa de 375,15/100 mil hab. Já Ouricuri teve taxa de 252,5/100 mil hab.

Em 2018, a taxa do Recife foi de 677,6/100 mil hab. Araripina apresentou taxa de 407,5/100 mil hab., e Ouricuri, de 295,2/100 mil hab. Assim, todas tiveram aumento na taxa de 2017 para 2018. Esses dados são importantes porque conseguem mostrar que, apesar de Araripina, por exemplo, ter menos de $10 \%$ da população total do Recife, sua taxa de violência contra a mulher é mais da metade da apresentada na capital.

A Tabela 1 apresenta dados no que diz respeito à distribuição de mulheres em situação de violência doméstica e familiar (VDF) por município na RD do Sertão do Araripe. Infelizmente, nenhuma das duas secretarias disponibiliza os dados com informações sobre os tipos de violência cometidos.

Tabela 1: Distribuição de mulheres vítimas de VDF por município

\begin{tabular}{lccccc}
\hline \multicolumn{1}{c}{ MUNICÍPIO } & $\mathbf{2 0 1 5}$ & $\mathbf{2 0 1 6}$ & $\mathbf{2 0 1 7}$ & $\mathbf{2 0 1 8}$ & Total \\
\hline Araripina & 235 & 269 & 290 & 319 & $\mathbf{1 . 1 1 3}$ \\
Bodocó & 47 & 50 & 64 & 91 & $\mathbf{2 5 2}$ \\
Exu & 58 & 54 & 55 & 74 & $\mathbf{2 4 1}$ \\
Granito & 4 & 5 & 8 & 18 & $\mathbf{3 5}$ \\
Ipubi & 65 & 69 & 71 & 94 & $\mathbf{2 9 9}$ \\
Moreilândia & 10 & 28 & 31 & 54 & $\mathbf{1 2 3}$ \\
Ouricuri & 161 & 152 & 155 & 190 & $\mathbf{6 5 8}$ \\
Santa Cruz & 6 & 12 & 8 & 26 & $\mathbf{5 2}$ \\
Santa Filomena & 5 & 13 & 7 & 26 & $\mathbf{5 1}$ \\
Trindade & 102 & 98 & 89 & 108 & $\mathbf{3 9 7}$ \\
Total & $\mathbf{6 9 3}$ & $\mathbf{7 5 0}$ & $\mathbf{7 7 8}$ & $\mathbf{1 . 0 0 0}$ & $\mathbf{3 . 2 2 1}$ \\
\hline
\end{tabular}

Fonte: Pernambuco (2019d).

Conforme os dados apresentados, há uma divergência com o Gráfico 1 em relação ao ano de 2018. Isso porque a Secretaria de Defesa Social atualizou os números posteriormente à divulgação do relatório da Secretaria da Mulher.

2 Para o cálculo da taxa, foram utilizados os dados apresentados pelo IBGE, pelo IBGE-Cidades. Disponível em: https://bit.ly/2VCcgKD. Acesso em: 5 mar. 2020. 
Pode-se perceber que, no ano de 2017, Araripina registrou 290 casos de violência doméstica e familiar, representando $37,27 \%$ do total de toda a região; em 2018, esse número passou para 319 casos registrados - 31,9\% do total. Em Ouricuri, no ano de 2017, foram registrados 155 casos de violência doméstica e familiar, 19,9\% dos casos na região; em 2018 esse número passou para 190 casos no município, representando $19 \%$ dos casos registrados em toda a região.

Em Araripina, entre os anos de 2017 e 2018, houve o aumento de 9,8\% no número de casos de violência doméstica e familiar; já em Ouricuri, esse acréscimo foi de pouco mais de $22 \%$. Apesar do aumento dos casos em ambos os municípios, os percentuais dentro da região diminuíram, pois houve expansão de casos em outras cidades. Chama-nos atenção os municípios: Granito, que passou de oito casos, em 2017, para dezoito em 2018, aumento de mais de 100\%; Santa Cruz, que passou de oito registros, em 2017, para 26 em 2018, representando aumento de quase 230\%; e Santa Filomena, que registou sete casos em 2017 e 26 em 2018, com aumento de mais de 250\%.

Esses números levantam a seguinte questão: esse aumento se deve, de fato, ao crescimento da violência ou às mulheres da região passarem a denunciar mais? As mulheres podem estar cada vez mais compreendendo que a dominação masculina é uma produção cultural e histórica que ocasionou as divisões de gênero (OLIVEIRA, 2002) e, assim, começam a ressignificar as práticas sociais definidas para cada gênero, compreendendo que não há uma natureza violenta no homem, tampouco uma passividade na mulher, que deve aguentar as violências calada.

No tocante aos crimes violentos letais e intencionais contra mulheres (CVLI-M), segundo informações da Secretaria Estadual da Mulher (PERNAMBUCO, 2019b), a região apresentou média de 7,5 mortes entre os anos 2015 a 2018, conforme o Gráfico 2.

Gráfico 2: Crimes violentos letais e intencionais contra mulheres (CVLI-M) (2015-2018)

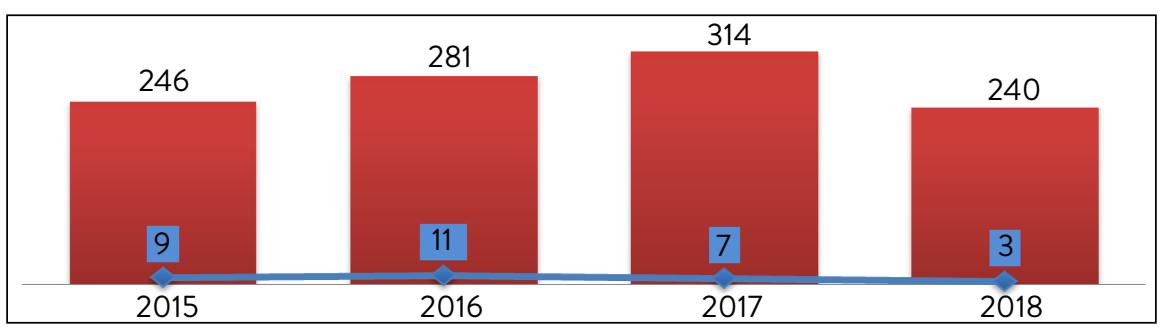

Legenda: CVLI de Mulheres em Pernambuco; $\rightarrow$ Sertão do Araripe: CVLI de Mulheres no Sertão do Araripe. Fonte: Pernambuco (2019b). 
Comparando os dados do Gráfico 2 com o número de CVLI total, apresentado pela Secretaria de Defesa Social (PERNAMBUCO, 2019c), percebe-se que a Região Metropolitana teve $6,41 \%$ de homicídios de mulheres em 2017 (154 de 2.401), enquanto o sertão do Araripe teve 6,03\% de CVLI femininos (sete do total de 116). Em 2018, a Região Metropolitana praticamente manteve o mesmo percentual - 6,4\% (121 de 1.879), apresentando redução no CVLI total e de mulheres; na RD sertão do Araripe, no CVLI total, a porcentagem de morte de mulheres foi de apenas 4,05\% em 2018 (três do total de 74).

número parece muito pequeno; no entanto, quando o relacionamos com a taxa de habitantes, os dados ficam mais significativos. A taxa de CVLI total (ou seja, para homens e mulheres) do municipio de Araripina em 2018 foi de 31,36/100 mil habitantes, não muito distante da taxa do Recife, que foi de 36,85/100 mil hab. Já Ouricuri apresenta taxa bem menor: 26,73/100 mil hab. (PERNAMBUCO, 2019d). A Tabela 2 apresenta dados da distribuição de CVLI por município na RD do sertão do Araripe.

Tabela 2: Distribuição de mulheres vítimas de CVLI por município

\begin{tabular}{lccccc}
\hline \multicolumn{1}{c}{ MUNICÍPIO } & $\mathbf{2 0 1 5}$ & $\mathbf{2 0 1 6}$ & $\mathbf{2 0 1 7}$ & $\mathbf{2 0 1 8}$ & Total \\
\hline Araripina & 3 & 4 & 3 & 1 & $\mathbf{1 1}$ \\
Bodocó & - & 1 & 1 & - & $\mathbf{2}$ \\
Exu & - & - & 2 & - & $\mathbf{2}$ \\
Granito & - & - & - & - & $\mathbf{0}$ \\
Ipubi & - & 2 & 1 & - & $\mathbf{3}$ \\
Moreilândia & - & - & - & 1 & $\mathbf{1}$ \\
Ouricuri & 4 & 1 & - & - & $\mathbf{5}$ \\
Santa Cruz & 1 & 2 & - & - & $\mathbf{3}$ \\
Santa Filomena & - & - & - & - & $\mathbf{0}$ \\
Trindade & 1 & 1 & - & 1 & $\mathbf{3}$ \\
Total & $\mathbf{9}$ & $\mathbf{1 1}$ & $\mathbf{7}$ & $\mathbf{3}$ & $\mathbf{3 0}$ \\
\hline
\end{tabular}

Fonte: Pernambuco (2019b).

Segundo dados da Secretaria de Defesa Social (PERNAMBUCO, 2019c), em Araripina, no ano de 2017, foram registrados 35 CVLI dos quais três foram contra mulheres, um percentual de 8,57\%. Em 2018, foram registrados $26 \mathrm{CVLI}$, dos quais um foi praticado contra mulheres, representando $3,84 \%$ dos CVLI cometidos no município. No município de Ouricuri, em 2017, foram registrados 13 CVLI; e em 2018, foram 19. Em nenhum dos dois anos houve homicídio de mulheres. 
Observou-se que, entre os anos de 2017 e 2018, em Araripina, houve decréscimo de aproximadamente $25 \%$ no que se refere aos casos gerais de CVLI. Nos casos de CVLI contra as mulheres, a diminuição foi de mais de $50 \%$. Chama-nos atenção o fato que o município de Ouricuri apresentava percentual de CVLI de mulheres de 16,7\% em 2016 (quatro mortes do total de 24), e caiu para zero em 2017 e 2018.

O Mapa da Violência apontou que, entre os anos de 2003 e 2013, Pernambuco conseguiu reduzir em $15,6 \%$ a taxa anual de homicídios de mulheres. Vale retomar que o estado caiu da $5^{a}$ para a $15^{a}$ posição no ranking nacional (WAISELFISZ, 2015). De fato, excetuando-se o ano de 2016, a região do Araripe vem seguindo a tendência estadual e diminuindo os casos de homicídios de mulheres.

Em consonância com a Lei n ${ }^{0} 13.104 / 2015$, visando ao melhor cumprimento da referida legislação, o estado de Pernambuco elaborou um protocolo de ações por meio do Decreto $n^{0} 44.950 / 2017$. Este retirou o termo "crime passional" do registro de ocorrência, incluindo o termo feminicídio para se referir aos CVLI cometidos contra a mulher em situação de violência doméstica e familiar, ou por razão de menosprezo da condição de sexo feminino (PERNAMBUCO, 2018).

No que diz respeito ao quantitativo de feminicídios registrados, o Gráfico 3 apresenta informações relativas ao número de crimes cometidos em todo o estado de Pernambuco e na RD do sertão do Araripe entre os anos de 2016 a 2018. Ressalta-se que, devido à Lei do Feminicídio ser de 2015, não há dados desse ano.

Gráfico 3: Registros de feminicídios (2016-2018)

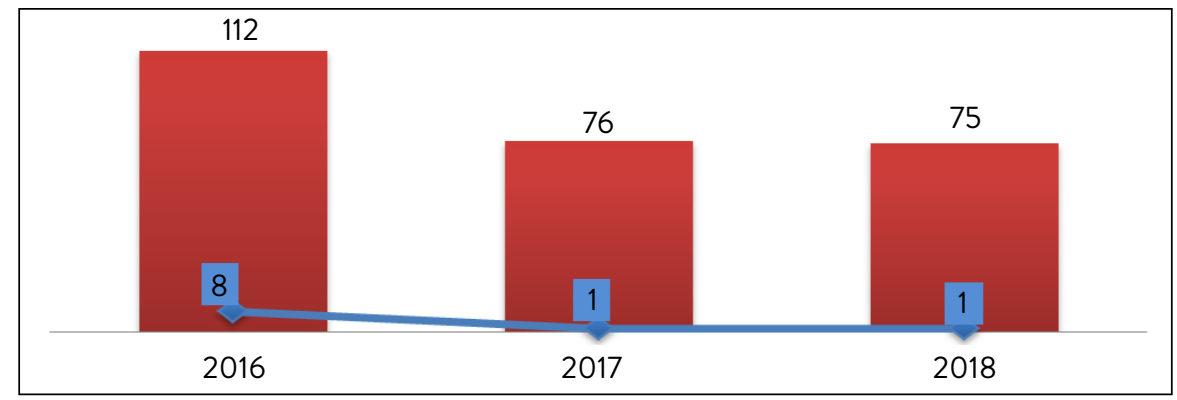

Legenda: Feminicídio em Pernambuco; $\rightarrow$ Feminicídio no sertão do Araripe. Fonte: Pernambuco (2019b). 
Em 2016, foram registrados 112 feminicídios em todo o estado, dentre os quais oito foram cometidos na RD do sertão do Araripe, representando 7,14\% do total. Em 2017, o percentual na RD foi de 1,31\% (um feminicidio dos 76 registrados no estado). Em 2018, a taxa foi de 1,33\% (um feminicídio dos 75 registrados no estado). Observou-se que, entre 2016 e 2017, houve diminuição de $19,44 \%$ no número de feminicídios na RD do sertão do Araripe e, entre 2017 e 2018, não houve decréscimo.

A Tabela 3 apresenta a distribuição por municípios dos registros de feminicídio. Pode-se observar que, em Araripina, no ano de 2016, a taxa de feminicídios em relação à RD do sertão do Araripe foi de 12,5\%. Em 2017 não houve percentual e, em 2018, este foi de 100\%. Já em Ouricuri, no ano de 2016, o percentual de feminicídios em relação à RD do sertão do Araripe foi de 12,5\%. Em 2017 e 2018 não houve registros de feminicídios.

Salienta-se a importância de citar outros marcos legais do estado de Pernambuco no que diz respeito à questão do feminicídio. Primeiro, o Decreto $n^{0} 44.951 / 2017$ instituiu o Grupo de Trabalho Interinstitucional sobre Feminicídio (GTIF), com o intuito de aplicar as diretrizes nacionais para investigar, processar e julgar as mortes violentas de mulheres a partir de uma perspectiva de gênero. E a Lei n 16.196/2017 instituiu o dia 5 de abril como o Dia Estadual de Combate ao Feminicídio. A data é em alusão ao assassinato de Mirella Sena, que foi estuprada e morta dentro de sua residência (PERNAMBUCO, 2018).

Tabela 3: Distribuição de mulheres vítimas de feminicídio por município

\begin{tabular}{lcccc}
\hline \multicolumn{1}{r}{ MUNICÍPIO } & $\mathbf{2 0 1 6}$ & $\mathbf{2 0 1 7}$ & $\mathbf{2 0 1 8}$ & Total \\
\hline Araripina & 1 & - & 1 & $\mathbf{2}$ \\
Bodocó & 1 & - & - & $\mathbf{1}$ \\
Exu & - & 1 & - & $\mathbf{1}$ \\
Granito & - & - & - & $\mathbf{0}$ \\
Ipubi & 2 & - & - & $\mathbf{2}$ \\
Moreilândia & - & - & - & 0 \\
Ouricuri & 1 & - & - & 1 \\
Santa Cruz & 2 & - & - & 2 \\
Santa Filomena & - & - & - & 0 \\
Trindade & 1 & - & - & 1 \\
Total & $\mathbf{8}$ & $\mathbf{1}$ & $\mathbf{1}$ & $\mathbf{1 0}$ \\
\hline
\end{tabular}

Fonte: Pernambuco (2019b). 
No que se refere às medidas protetivas, Pernambuco dispõe de uma rede estadual composta por quatro casas-abrigo, localizadas em diferentes regiões do estado e com endereço sigiloso. As casas existem desde 2006 e, durante esse tempo, já atendeu 876 mulheres e 1.466 dependentes, totalizando 2.342 pessoas protegidas (dados referentes até junho de 2018). A Lei $n^{0} 13.977 / 2009$ instituiu oficialmente o serviço de abrigamento, atendimento e proteção às mulheres em situação de violência doméstica e familiar, sob risco de morte, no estado de Pernambuco. A Lei garante à mulher, de forma não compulsória, a possibilidade de permanecer na casa-abrigo por um período de até 120 dias ou se deslocar para um local que considere seguro dentro do território nacional (PERNAMBUCO, 2018).

A Tabela 4 apresenta dados referentes ao quantitativo de mulheres protegidas pelo serviço de abrigamento entre os anos de 2015 a 2018, provenientes da região do Araripe. Observa-se que, durante o período de 2015 a 2018, na RD do sertão do Araripe, Araripina foi a cidade que mais encaminhou mulheres para as casas-abrigo, enquanto Ouricuri apresenta apenas um encaminhamento no ano de 2015.

Tabela 4: Quantitativo de mulheres protegidas pelo serviço de abrigamento no período de 2015 a 2018

\begin{tabular}{lccccc}
\hline \multicolumn{1}{c}{ MUNICÍPIOS } & $\mathbf{2 0 1 5}$ & $\mathbf{2 0 1 6}$ & $\mathbf{2 0 1 7}$ & $\mathbf{2 0 1 8}$ & Total \\
\hline Araripina & 3 & 2 & 2 & - & $\mathbf{7}$ \\
Bodocó & - & - & - & 1 & 1 \\
Exu & - & - & - & - & $\mathbf{0}$ \\
Granito & 1 & - & - & - & $\mathbf{1}$ \\
Ipubi & - & - & - & - & $\mathbf{0}$ \\
Moreilândia & - & - & - & - & 0 \\
Ouricuri & 1 & - & - & - & $\mathbf{1}$ \\
Santa Cruz & - & - & - & 1 & $\mathbf{1}$ \\
Santa Filomena & - & - & - & - & 0 \\
Trindade & - & - & - & - & 0 \\
Total & $\mathbf{5}$ & $\mathbf{2}$ & $\mathbf{2}$ & $\mathbf{2}$ & $\mathbf{1 1}$ \\
\hline
\end{tabular}

Fonte: Pernambuco (2019b).

Enquadrados no Programa Justiça para as Mulheres, que institui ações de impacto no enfrentamento da violência de gênero no estado de Pernambuco, pode-se ainda mencionar os seguintes serviços: o 190 
Mulher, a Patrulha Maria da Penha e o Monitoramento Eletrônico para Agressores de Mulheres. Entre o período de janeiro de 2015 a junho de 2018, esse programa protegeu 12.728 mulheres em todo o estado (PERNAMBUCO, 2018).

A Portaria Conjunta da Secretaria de Defesa Social e Secretaria da Mulher $n^{0}$ 053, de 2015, instituiu o serviço 190 Mulher. $\bigcirc$ principal objetivo é prestar atendimento prioritário às ocorrências envolvendo mulheres em situação de violência doméstica e sexual, sob o risco iminente de morte. A ação deve ser realizada pelo Centro Integrado de Operações de Defesa Social (Ciods) (PERNAMBUCO, 2018). A Tabela 5 apresenta o número de mulheres que acionaram o serviço durante os anos de 2015 a 2018.

A Portaria Conjunta da Secretaria de Justiça e Direitos Humanos (SJDH) e da Secretaria da Mulher, $n^{0}$ 050/2015, instituiu o serviço de Monitoramento Eletrônico da Lei Maria da Penha. $O$ principal objetivo é garantir a proteção das mulheres em situação de violência doméstica e familiar no estado, pelo monitoramento eletrônico de reeducandos. Trata-se de uma ação realizada pela Secretaria Executiva de Ressocialização (Seres) que e tem como fundamento o art. 39, inciso IX do Código do Processo Penal, bem como a Lei $n^{0} 11.340 / 2006$ (PERNAMBUCO, 2018). A Tabela 6 apresenta os dados do serviço no sertão do Araripe.

Tabela 5: Quantitativo de mulheres protegidas pelo serviço 190 Mulher no período de 2015 a 2018

\begin{tabular}{lccccc}
\hline \multicolumn{1}{c}{ MUNICÍPIOS } & 2015 & 2016 & 2017 & 2018 & Total \\
\hline Araripina & 1 & - & - & - & 1 \\
Bodocó & - & - & - & - & 0 \\
Exu & - & - & - & - & 0 \\
Granito & - & - & - & - & 0 \\
Ipubi & - & - & - & - & 0 \\
Moreilândia & - & - & - & - & 0 \\
Ouricuri & - & - & - & - & 0 \\
Santa Cruz & - & - & - & - & 0 \\
Santa Filomena & - & - & - & - & 0 \\
Trindade & - & - & - & - & 0 \\
Total & 1 & 0 & 0 & 0 & 1 \\
\hline
\end{tabular}

Fonte: Pernambuco (2019b). 
Tabela 6: Quantitativo de mulheres protegidas pelo

Monitoramento Eletrônico no período de 2015 a 2018

\begin{tabular}{lccccc}
\hline \multicolumn{1}{c}{ MUNICÍPIOS } & 2015 & 2016 & 2017 & 2018 & Total \\
\hline Araripina & - & - & - & - & 0 \\
Bodoć & - & - & - & - & 0 \\
Exu & - & - & - & - & 0 \\
Granito & - & - & - & - & 0 \\
Ipubi & - & - & - & - & 0 \\
Moreilândia & - & - & - & - & 0 \\
Ouricuri & - & - & - & - & 0 \\
Santa Cruz & - & - & - & - & 0 \\
Santa Filomena & - & - & - & - & 0 \\
Trindade & - & - & - & - & 0 \\
Total & 0 & 0 & 0 & 0 & 0 \\
\hline
\end{tabular}

Fonte: Pernambuco (2019b).

A Portaria Conjunta da Secretaria de Defesa Social e da Secretaria da Mulher $n^{0}$ 041/2015 instituiu o serviço de Patrulha Maria da Penha. Seu principal objetivo é garantir a proteção das mulheres em situação de violência doméstica e familiar no estado, por meio da atuação da Polícia Militar (PERNAMBUCO, 2018). O serviço ainda não foi implantado na região do Araripe.

\section{Considerações finais}

A partir das lutas das mulheres para garantir seus direitos básicos, não se pode negar que houve avanços e conquistas, no entanto ainda é preciso progredir para garantir não apenas a visibilidade e a efetividade desses direitos, mas, acima de tudo, que estes sejam respeitados. Assim será possivel uma sociedade que reduza significativamente o número de mulheres violadas e/ou violentadas.

Neste artigo, procurou-se evidenciar a correlação entre gênero e regionalidade. A construção do espaço geográfico nordeste-sertão esteve historicamente agregada a uma imagem de lugar de seca, miséria e violência. Com isso, a construção do homem nordestino-sertanejo seguiu o mesmo caminho: a masculinidade e a violência seriam características do ser nordestino (ALBUQUERQUE JÚNIOR, 1998), pois nessa região não haveria lugar para homens fracos e covardes. 
$\mathrm{Na}$ construção do homem nordestino-sertanejo, em consequência, também foi construída a ideia da mulher nordestina-sertaneja. Seu lugar é de silêncio, de enxada, de luta ao lado do marido, de mãe, de esposa dedicada, ligada à esfera doméstica. Conforme pontua Albuquerque Júnior (1998), essas relações entre os gêneros reproduzem e perpetuam violências que, no contexto do sertão, estão estritamente ligadas aos fenômenos do cangaço e do coronelismo, que reforçam a ideia do homem sertanejo como valente, viril e destemido.

Diante dos dados analisados da região do sertão do Araripe de Pernambuco, é possível prescindir a perpetuação da violência contra a mulher. Embora os números pareçam muitas vezes inexpressivos e/ou pequenos, o recorte de gênero e região são mais importantes. Assim, chama-nos atenção o fato de a taxa de CVLI total do município de Araripina (31,36/100 mil hab.) para 2018 não ser muito distante da taxa do Recife (36,85/100 mil hab.).

Além disso, em todos os municípios da região houve aumento nos registros de violência doméstica e familiar contra a mulher. Araripina e Ouricuri continuam como os municípios com mais casos, porém com percentuais menores dentro da região como um todo. Este fato se deve ao aumento significativo dos casos registrados nos municípios do Granito, Santa Cruz e Santa Filomena, tendo este último ampliação de mais de $250 \%$ entre os anos 2017 e 2018.

Sabe-se que esse aumento pode significar o crescimento da divulgação dos direitos das mulheres, principalmente da Lei ${ }^{0} 11.340 / 2006$ e dos seus dispositivos, mas os dados apresentados não permitem realizar esse tipo de leitura. É necessária uma análise pormenorizada dos casos existentes acompanhados pelos equipamentos que realizam atendimento de mulheres em situação de violência nos municípios da região.

Pode-se notar, pelas Tabelas 4, 5 e 6, que, entre os anos de 2015 a 2018, de forma geral, os municípios da região do sertão do Araripe acessaram pouco os serviços de proteção às mulheres em situação de violência doméstica e familiar, em especial o 190 Mulher e o Monitoramento Eletrônico. $\bigcirc$ Serviço de Abrigamento protegeu onze mulheres durante todo o período analisado. Comparando o número de mulheres atendidas pelos serviços com o número de casos de morte de mulheres e vítimas de violência doméstica e familiar (Tabelas 1, 2 e 3), constata-se a necessidade de expandir a divulgação e a oferta dos serviços às mulheres, assim como de 
buscar maior integração e articulação com o judiciário e os demais serviços nos municípios.

Assim, compreende-se que a eficácia das ações de prevenção e redução da violência contra a mulher depende da reunião de recursos de diversas áreas e, com isso, é preciso criar uma rede ampla de enfrentamento. Ressalta-se, por fim, que os três pilares tidos como fundamentais para a efetivação do trabalho - a prevenção, a assistência e o combate à violência - devem ser pautados sempre interseccionando os marcadores de gênero e regionalidade, pois é imprescindivel a ressignificação das relações de gênero, que muitas vezes acabam vulnerabilizando as mulheres, principalmente no sertão nordestino.

\section{Referências}

ALBUQUERQUE JÚNIOR, D. M. O engenho anti-moderno: a invenção do nordeste. 1994. Tese (Doutorado em História) - Universidade Estadual de Campinas, Campinas, 1994.

ALBUQUERQUE JÚNIsOR, D. M. Mole não se mete: a violência como elemento constitutivo da identidade do nordestino. Campina Grande: UFPB, 1998.

ALBUQUERQUE JÚNIOR, D. M. Nordestino: invenção do falo. Uma história do gênero masculino (1920-1940). 2. ed. São Paulo: Intermeios, 2013.

BLAY, E. A. Violência contra a mulher e políticas públicas. Estudos Avançados, São Paulo, v. 17, n. 49, p. 87-98, 2003.

BRASIL. Código Civil dos Estados Unidos do Brasil. Diário Oficial [da] República Federativa do Brasil: seção 1, Brasilia, DF, p. 133, 5 jan. 1916. (Norma revogada expressamente).

BRASIL. Constituição da República Federativa do Brasil. Diário Oficial [da] República Federativa do Brasil: seção 1, Brasilia, DF, p. 1, 5 out. 1988.

BRASIL. Lei $n^{0}$ 9.099, de 26 de setembro de 1995. Diário Oficial [da] República Federativa do Brasil: seção 1, Brasília, DF, p. 15.033, 27 set. 1995. 
BRASIL. Lei n ${ }^{10.406, ~ d e ~} 10$ de janeiro de 2002 (Código Civil 2002). Diário Oficial da União: seção 1, Brasília, DF, p. 1, 11 jan. 2002.

BRASIL. Lei n ${ }^{0} 11.340$, de 7 de agosto de 2006. Cria mecanismos para coibir a violência doméstica e familiar contra a mulher. Diário Oficial da União: seção 1, Brasillia, DF, p. 1, 8 ago. 2006.

BRASIL. Lei n 13.104, de 9 de março de 2015. Diário Oficial da União: seção 1, Brasilia, DF, p. 1, 10 mar. 2015.

BRASIL. Lei n ${ }^{0}$ 13.827, de 13 de maio de 2019. Diário Oficial da União: seção 1, Brasilia, DF, nº 91, p. 3, 14 mai. 2019.

CERQUEIRA, D. et al. Atlas da Violência 2019. Brasilia, DF: Instituto de Pesquisa Econômica Aplicada, 2019.

FUNDAÇÃO JOAQUIM NABUCO. Pesquisa: condições de vida dos adolescentes e jovens urbanos dos municípios de Trindade, Araripina e Ouricuri. Relatório Final. Recife, 2006.

institutO BRASILEIRO DE GeOgrafia e estatístiCA. Censo demográfico 2010. Rio de Janeiro, 2011. Disponivel em: https://bit.ly/3gjMF1f. Acesso em: 30 mar. 2020.

LOURO, G. L. Gênero, sexualidade e educação: uma perspectiva pósestruturalista. Petrópolis: Vozes, 1996.

MINAYO, M. C. S. Conceitos, teorias e tipologias de violência: a violência faz mal à saúde. In: NJAINE, K.; CONSTANTINO, P.; ASSIS, S. G. (org.). Impactos da violência na saúde. Rio de Janeiro: Fiocruz, 2007. p. 21-42.

MOLION, L. C. B.; BERNARDO, S. O. Uma revisão da dinâmica das chuvas no nordeste brasileiro. Revista Brasileira de Meteorologia, São José dos Campos, v. 17, p. 1-10, 2002.

OLIVEIRA, I. B. Façamos a família à nossa imagem: a construção de conceitos de família no Recife moderno (décadas de 20 e 30). 2002. Tese (Doutorado em História) - Universidade Federal de Pernambuco, Recife, 2002. 
PASINATO, W. Lei Maria da Penha: novas abordagens sobre velhas propostas. Onde avançamos? Revista de Ciências Sociais, São Paulo, v. 10, n. 2, p. 216-232, 2010.

PERNAMBUCO. Protocolo de feminicídio de Pernambuco: diretrizes estaduais para prevenir, investigar, processar e julgar as mortes violentas de mulheres com perspectiva de gênero. Recife: Câmara Técnica de Enfrentamento da Violência de Gênero contra a Mulher do Pacto pela Vida, 2018.

PERNAMBUCO. Perfil municipal. SIGAS, Recife, 2019a. Disponivel em: https://bit.ly/2YMC20Q. Acesso em: 2 abr. 2020.

PERNAMBUCO. Sistema Estadual de Informação sobre as Mulheres (SeiMulheres). Recife: Secretaria da Mulher de Pernambuco, 2019b.

PERNAMBUCO. Estatísticas: Crimes Violentos Letais e Intencionais. Recife: Secretaria de Defesa Social de Pernambuco, 2019c. Disponivel em: https://bit.ly/2BXABDC. Acesso em: 17 mar. 2020.

PERNAMBUCO. Estatísticas: Violência Doméstica e Familiar contra a Mulher. Recife: Secretaria de Defesa Social de Pernambuco, 2019d. Disponivel em: https://bit.ly/3gbYbeU. Acesso em: 17 mar. 2020.

PIOVESAN, F.; PIMENTEL, S. A Lei Maria da Penha na perspectiva da responsabilidade internacional do Brasil. In: CAMPOS, C. H. (org.). Lei Maria da Penha comentada em uma perspectiva jurídico-feminista. Rio de Janeiro: Lumen Juris, 2011. p. 101-118.

PRADO, D. E. As caatingas da América do Sul. In: LEAL, I. R.; TABARELI, M.; SILVA, J. M. C. (ed.). Ecologia e conservação da Caatinga. Recife: Universidade Federal de Pernambuco, 2003. p. 3-74.

PRADO, D; SANEMATSU, M. (org.). Feminicidío: \#InvisibilidadeMata. São Paulo: Instituto Patrícia Galvão, 2017.

SANTOS, C. M.; IZUMINO, W. P. Violência contra as mulheres e violência de gênero: notas sobre estudos feministas no Brasil. Estudios Interdisciplinarios de América Latina y el Caribe, Tel Aviv, v. 16, n. 1, p. 147-164, 2005. 
SCOTT, J. W. Gênero: uma categoria útil de análise histórica. Educação \& Realidade, Porto Alegre, v. 20, n. 2, p. 71-99, 1995.

WAISELFISZ, J. J. Mapa da violência 2015: homicídio de mulheres no Brasil. São Paulo: Instituto Sangari, 2015.

Recebido em abril de 2020.

Aprovado em junho de 2020. 